\title{
Canadian Cardiovascular Harmonized National Guidelines Endeavour (C-CHANGE) guideline for the prevention and management of cardiovascular disease in primary care: 2018 update
}

Sheldon W. Tobe MD MScCH, James A. Stone MD PhD, Todd Anderson MD, Simon Bacon PhD, Alice Y.Y. Cheng MD, Stella S. Daskalopoulou MD PhD, Justin A. Ezekowitz MBBCh MSc, Jean C. Grégoire MD, Gord Gubitz MD, Rahul Jain MD MScCH, Karim Keshavjee MSc MD, Patty Lindsay RN PhD, Mary L’Abbé PhD, David C.W. Lau MD PhD, Lawrence A. Leiter MD, Eileen O’Meara MD, Glen J. Pearson PharmD, Doreen M. Rabi MD MSc, Diana Sherifali RN PhD, Peter Selby MBBS MHSc, Jack V. Tu MD PhD, ^ Sean Wharton MD PharmD, Kimberly M. Walker MPH, Diane Hua-Stewart MPH, Peter P. Liu MD

- Cite as: CMAJ 2018 October 9;190:E1192-206. doi: 10.1503/cmaj.180194

CMAJ Podcasts: author interview at https://soundcloud.com/cmajpodcasts/180194-guide

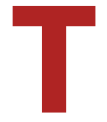
he Canadian Cardiovascular Harmonized National Guideline Endeavour (C-CHANGE) is a nationally endorsed guideline process, targeting primary care health care practitioners. The C-CHANGE guideline is a composite of nine of Canada's cardiovascular-focused clinical practice guidelines (Table 1), chosen to meet primary care needs, including managing patients with multiple comorbidities, and since 2011 has been part of Canada's robust and successful cardiovascular guideline efforts. ${ }^{8,9}$ Ninety percent of Canadians still have suboptimal cardiovascular health from multiple cardiovascular risk factors, higher rates of obesity and diabetes, ${ }^{15}$ and suboptimal control of hypertension, dyslipidemia and blood glucose. ${ }^{16}$ The compilation of the best available evidence into a nationally recognized and valuable set of best practices provides a common starting point for local and regional implementation strategies to achieve target control rates, including the enabling of interprofessional care. Putting evidence-based best practices into the hands of primary care health care practitioners may accelerate improved outcomes in Canada, but the main challenge is how best to implement the new recommendations, with efforts cognizant of local context and tailored to the needs of regional and local populations. The goal of the C-CHANGE process is for all Canadian health care practitioners to have easy access to a comprehensive and usable set of harmonized guidelines.

The third cycle of the C-CHANGE process was initiated as a result of many updates to the participating guidelines, including

\section{KEY POINTS}

- C-CHANGE promotes patient care by bringing nine guideline groups together, to provide a composite set of recommendations to help clinicians formulate a comprehensive treatment plan directed toward patient priorities.

- The 2018 update to the C-CHANGE guideline includes a total of 77 recommendations and 52 recommendations that are newly added or updated.

- A new category for hypertension for high-risk individuals has been developed with a new lower threshold for treatment $(130 \mathrm{~mm} \mathrm{Hg}$ systolic) and target blood pressure (< $120 \mathrm{~mm} \mathrm{Hg} \mathrm{systolic).}$

- Multifaceted care for patients with cardiovascular risks includes the cornerstones of health behaviour change, such as healthy eating and regular physical activity.

a complete update of the Canadian Association of Cardiovascular Prevention and Rehabilitation and Obesity Canada guidelines and the addition of guidelines on heart failure. In each C-CHANGE cycle, efforts are made to improve and harmonize guideline development with all partner organizations so that each guideline scores highly on the AGREE II (Appraisal of Guidelines for Research \& Evaluation II) Instrument, which evaluates the process of guideline development and quality of reporting. ${ }^{17}$

The full 2018 C-CHANGE guideline update is available in Appendix 1, at www.cmaj.ca/lookup/suppl/doi:10.1503/cmaj .180194/-/DC1. 


\section{Scope}

This guideline is directed to primary health care providers caring for Canadian adults who have or are at risk of developing chronic cardiovascular diseases, including hypertension, diabetes, dyslipidemia, heart failure and stroke, and the risk factors for these conditions, including smoking, obesity and physical inactivity. The purpose of the C-CHANGE guideline is to bring together a comprehensive set of recommendations drawn from the nine participating guideline groups applicable to the care of people with multiple comorbidities. The aim is also to do this with sufficient rigour that health care practitioners and patients have confidence in the C-CHANGE process, as well as in the guidelines from the nine participating groups.

\section{Methods}

\section{Guideline panel composition}

This C-CHANGE guideline update was developed by a volunteer guideline panel, which is a scientific committee that reflects the authors of this paper and draws representation from each of the guideline partner organizations involved in the C-CHANGE process, along with primary care physicians with expertise in guideline dissemination (Appendix 2, available at www.cmaj.ca/ lookup/suppl/doi:10.1503/cmaj.180194/-/DC1). C-CHANGE works with each of the guideline groups to support quality improvement in guideline development in the domains outlined by the
AGREE II Instrument. ${ }^{17}$ The C-CHANGE process uses a modified Delphi method to select a subset of all of the guideline partners' recommendations that are appropriate for a primary care setting. ${ }^{8}$ Appendix 3, available at www.cmaj.ca/lookup/suppl/ doi:10.1503/cmaj.180194/-/DC1, outlines the process and timeline undertaken for the 2018 C-CHANGE update.

\section{Guideline development}

In the fall of 2016, the C-CHANGE guideline groups were contacted and agreed to participate in a consensus conference in June of 2017, as there were sufficient updates in the individual guideline groups to justify a C-CHANGE update and there was also the possibility that the heart failure guidelines would be ready for this C-CHANGE cycle (Appendix 3). Individual recommendations are chosen from each guideline group for inclusion in C-CHANGE to meet the needs of patients with the most common clusters of comorbidities, as hypertension, diabetes and dyslipidemia cluster together. ${ }^{18}$

The Canadian Cardiovascular Society's heart failure group had been working with C-CHANGE for the last three years to update its guideline process and became the ninth major guidelines group to join the C-CHANGE collaboration. The addition of the heart failure recommendations had to wait until they were published in October 2017. From the 2017 comprehensive update of the Canadian Cardiovascular Society heart failure guideline, eight specific recommendations were chosen, using the modified Delphi process, as being the most appropriate for

Table 1: C-CHANGE guideline partners and methodology

Guideline group

Canadian Action Network for the Advancement, Dissemination and Adoption of Practice-Informed Tobacco Treatment ${ }^{1}$

Canadian Cardiovascular Society - guideline for the management of heart failure ${ }^{3}$

Canadian Cardiovascular Society - guideline for the management of dyslipidemia ${ }^{4}$

Canadian Association of Cardiovascular Prevention and Rehabilitation

Canadian Society for Exercise Physiology ${ }^{5}$

Diabetes Canada ${ }^{10}$

Hypertension Canada ${ }^{11}$

Canadian Association of Bariatric Physicians and

Surgeons/Obesity Canada ${ }^{12}$

Heart and Stroke Foundation ${ }^{13}$

\section{Grading system or methodology}

This independent expert body in guideline review conducted a review and identified 6 guidelines that met criteria for quality and applicability to local context. Summary statements were extracted and assigned a grade of recommendation and level of evidence by a second expert panel. ${ }^{2}$ The ADAPTE framework was used to guide the contextual adaptation (www.g-i-n.net/working-groups/adaptation/history); AGREE II was used to rate and select appropriate guidelines.

GRADE

GRADE

Hypertension Canada process (www.hypertension.ca)

The Canadian Society for Exercise Physiology guideline steering committee used the AMSTAR tool (www.amstar.ca/docs/AMSTARguideline.pdf) to assess the methodological quality of the systematic reviews; conclusions from the reviews were assigned a level of evidence ${ }^{6-9}$ based on quality of the study, and level of evidence was used to develop appropriate wording for the guideline.

Diabetes Canada process (www.guidelines.diabetes.ca/)

Hypertension Canada process (www.hypertension.ca)

GRADE

GRADE 
primary care health care practitioners, and were added to the C-CHANGE guideline. ${ }^{3}$ Agreements were established between the guideline groups about timing of publication of C-CHANGE and each individual group.

C-CHANGE ensures the quality of each partner guideline group using the AGREE II Instrument ${ }^{17}$ to assess the quality and reporting of the guideline. C-CHANGE performs an appraisal using AGREE II for the guideline groups; the appraisals can be found online (www.cchangeguidelines.com). For more information on using AGREE II and the quality improvement process, see Appendix 4, available at www.cmaj.ca/lookup/suppl/ doi:10.1503/cmaj.180194/-/DC1 (Quality Improvement in C-CHANGE Guideline).

\section{Management of competing interests}

Funding for the C-CHANGE consensus conference and administrative support came from the Canadian Institutes of Health Research and in-kind support from the scientific and professional volunteers engaged in the process.

Seven of the nine guideline groups require their guideline panel members to disclose any potential competing interests by the time of their consensus conference, or early in the development process. Members with direct competing interests are asked to abstain from voting in the areas in which they have the conflict.

In the other two guideline groups, the Canadian Cardiovascular Society and the Canadian Action Network for the Advancement, Dissemination and Adoption of Practice-informed Tobacco Treatment, mitigation of competing interests and prevention of bias are approached by requiring a majority of their panel members in each guideline subgroup to have no relationships with industry; competing interests are declared early in the development process to ensure the required panel composition. In these two guideline subgroups, expert opinion from committee members with competing interests are welcomed at the consensus conference with the recognition of their potential bias. Experts in critical appraisal who have no competing interests make up the review committees to ensure the evidence has been assessed appropriately, and to provide a respected voice at the consensus discussions and debates, ensuring recommendations are aligned with the evidence. These experts in critical appraisal are part of the individual guideline

Table 2: Body habitus: New or updated recommendations in the 2018 C-CHANGE harmonized guideline*

Recommendation
Heart failure
We suggest daily morning weight should be
monitored in patients with heart failure,
with fluid retention or congestion that is not
easily controlled with diuretics, or in
patients with significant renal dysfunction.
Note: C-CHANGE = Canadian Cardiovascular Harmonized National Guidelines
Endeavour, HF = Canadian Cardiovascular Society - Heart Failure.
${ }^{*}$ All recommendations are considered strong recommendations (Box 1); the quality of
evidence supporting each recommendation varies (see Appendix 1 for a detailed
discussion of the supporting evidence).
†Based on consensus opinion.

groups and, for Diabetes Canada and Hypertension Canada, led the guideline development process (DS and DR, respectively). As leads of their respective processes, these two critical appraisal experts were also part of the C-CHANGE guideline process.

\section{Recommendations}

The 2018 update to the C-CHANGE guideline includes a total of 77 recommendations originating from the nine partner guideline groups, including 52 recommendations that have been newly added or updated (Tables 2-8). The ninth guideline (Canadian Cardiovascular Society Guidelines for the Management of Heart Failure) ${ }^{7}$ was added to C-CHANGE this year, with eight heart failure recommendations. The complete list of 2018 C-CHANGE recommendations is available in Appendix 1, with a full discussion of the evidence supporting each recommendation.

In the recommendations, it was important to keep the focus on multifaceted optimal medical care, which remains a goal for people with diabetes and, by extension, those at higher risk of cardiovascular disease (Box 2). Management of multifaceted care in the ambulatory care setting is facilitated with an interprofessional team approach.

\section{Box 1: Strength of recommendations and quality of evidence}

The individual guideline groups have a rigorous methodology to assess the quality of evidence for the development of guidelines, and these are listed in Table 1. There are two dimensions describing each of the recommendations: the first is the strength of the recommendation, and the second the quality of the evidence supporting it, based on quality and certainty. All Canadian Cardiovascular Harmonized National Guidelines Endeavour (C-CHANGE) recommendations are "should do" or "should not do" recommendations and are considered to be strong. A "must do" recommendation is usually a policy to comply with health and safety recommendations, such as hand washing; a "could do" recommendation is one that some patients may opt out of because other options are less effective but more acceptable. The National Institute for Health and Clinical Excellence describes "should do" and "should not do" recommendations as interventions that, in most people, will lead to more good than harm. ${ }^{6}$

The second dimension describing the recommendation is the evidentiary base. C-CHANGE works with the guideline groups to ensure that the evidence cited and systematic reviews are of the highest quality and reviewed by experts in critical appraisal who have no competing interests. For drug and device recommendations, the highest level of evidence is required from randomized controlled trials of hard outcomes with adequate power and appropriate internal and external validity. ${ }^{7}$ Health behaviour change and diagnostic recommendations can have evidence with surrogate outcomes. Every effort is made to reduce the number of recommendations that are based on consensus opinion only, but these are still considered strong recommendations, as most people would follow the expert opinion where sufficient evidence does not exist. Drug and device recommendations are not based on consensus opinion. C-CHANGE aims to select recommendations based on high-quality evidence and to minimize recommendations that are based on consensus ( 8 of the 76 recommendations [10.5\%] are consensus). 
Table 3: Diet, and sodium and alcohol intake: New or updated recommendations in the 2018 C-CHANGE harmonized guideline*

All

To prevent hypertension and reduce blood pressure in hypertensive adults, consider reducing sodium intake toward $2000 \mathrm{mg}$ ( $5 \mathrm{~g}$ of salt or $87 \mathrm{mmol}$ of sodium) per day.

We suggest that all individuals be encouraged to moderate energy (caloric) intake to achieve and maintain a healthy body weight and adopt a healthy dietary pattern to lower their risk of cardiovascular disease:

- Mediterranean dietary pattern

- Portfolio dietary pattern

- DASH dietary pattern

- Dietary patterns high in nuts $(\geq 30 \mathrm{~g} / \mathrm{d})$

- Dietary patterns high in legumes ( $\geq 4$ servings/wk)

- Dietary patterns high in olive oil $(\geq 60 \mathrm{~mL} / \mathrm{d})$

- Dietary patterns rich in fruits and vegetables ( $\geq 5$ servings/d)

- Dietary patterns high in total fibre ( $\geq 30 \mathrm{~g} / \mathrm{d}$ ); and whole grains ( $\geq 3$ servings/d)

- Low glycemic load or low glycemic index dietary patterns

- Vegetarian dietary patterns

\section{Diabetes}

People with diabetes should be offered timely self-management education that is tailored to enhancing self-care practices and behaviours.

\section{Overweight or obesity}

A dietary plan for improving health for adults with obesity should be part of a weight-management strategy. A comprehensive healthy lifestyle intervention is recommended for people with overweight and obesity.

$\mathrm{HC}^{19}$

$\mathrm{CCS}^{20}$

$\mathrm{DC}^{21}$

Obesity $^{23}$

Note: C-CHANGE = Canadian Cardiovascular Harmonized National Guidelines Endeavour, CCS = Canadian Cardiovascular Society - Dyslipidemia, DASH = Dietary Approaches to Stopping Hypertension, DC = Diabetes Canada (formerly Canadian Diabetes Association), HC = Hypertension Canada, Obesity = Obesity Canada.

${ }^{*}$ All recommendations are considered strong recommendations (Box 1); the quality of evidence supporting each recommendation varies (see Appendix 1, available at www.cmaj.ca/

lookup/suppl/doi:10-1503/cmaj.180194/-/DC1, for a detailed discussion of the supporting evidence. Key references are indicated in this table.)

\section{Major changes in recommendations}

\section{Hypertension}

The Systolic Blood Pressure Intervention Trial (SPRINT) study, published in November of 2015, has led to substantial changes in blood pressure measurement and management recommendations in Canada and the United States. ${ }^{64,65}$ After SPRINT's publication, a new category for hypertension for high-risk individuals was developed in Canada by Hypertension Canada with a new lower threshold for treatment (130 mm Hg systolic) and the lowest target blood pressure yet in any Canadian guideline $(<120 \mathrm{~mm} \mathrm{Hg}$ systolic). This large National Institutes of Health study has excellent internal and external validity and showed that the lower blood pressure target offered a substantial cardiovascular benefit for higher-risk patients who had a systolic blood pressure of $130 \mathrm{~mm} \mathrm{Hg}$ or more and the presence of a Framingham Risk Score of $15 \%$ or more, chronic kidney disease (estimated glomerular filtration rate [eGFR] $20-60 \mathrm{~mL} / \mathrm{min}$ ), or were aged 75 and older. The study did not include patients with diabetes or previous stroke, or those with postural hypotension, or who were unwilling to take intensified therapy. The results showed a relative risk reduction of cardiovascular events by $25 \%$ (95\% confidence interval [Cl]
$0.64-0.89)$ and total mortality by $27 \%(95 \% \mathrm{Cl} 0.60-0.90)$ at only 3.3 years and associated numbers needed to treat of 62 and 90 , respectively, over three years. ${ }^{65}$ The number needed to treat of the primary outcome over 3.14 years for participants aged 75 and older was 27 , and for frail compared with fit participants, there was greater absolute benefit. ${ }^{66}$

The SPRINT study was also consistent with the recent Hypertension Canada change in recommendation on blood pressure measurement in the office..$^{11}$ Automated oscillometric devices are now preferred over manual readings with aneroid or mercury sphygmomanometers, and home measurements or, preferably, ambulatory blood pressure monitoring are recommended for the diagnosis of hypertension. ${ }^{11,67-72}$ Measurement of blood pressure with automated devices in the waiting room and in the pharmacy has been shown to closely approximate home blood pressure monitoring, as well as daytime ambulatory blood pressure monitoring. ${ }^{73}$

Single-pill combinations are now recommended as initial therapy for patients with elevated blood pressure even less than 20/10 above target. The evidence comes from the improved adherence and efficacy of single-pill combinations and studies showing a reduction in cardiovascular events. ${ }^{74}$ 
Table 4 (part 1 of 2): Risk factor screening: New or updated recommendations in the 2018 C-CHANGE harmonized guideline*

\section{Recommendation}

Source guideline

All

Screening for diabetes using FPG and/or $A_{1 c}$ should be performed every $3 \mathrm{yr}$ in individuals aged $\geq 40 \mathrm{yr}$ or at high risk, using a risk calculator. Earlier testing and more frequent follow-up (every 6 to $12 \mathrm{mo}$ ) with either FPG and/or $\mathrm{A}_{1 \mathrm{c}}$ or $2 \mathrm{hPG}$ in a $75 \mathrm{~g}$ OGTT should be considered in those at very high risk, using a risk calculator, or in people with additional risk factors for type 2 diabetes. These risk factors include:

- Age $\geq 40 \mathrm{yr}$

- First-degree relative with type 2 diabetes

- Member of high-risk population (e.g., African, Arab, Asian, Hispanic, Indigenous or South Asian descent; low socioeconomic status)

- History of prediabetes (IGT, IFG or $\mathrm{A}_{1 \mathrm{c}} 6.0 \%-6.4 \%$ )

- History of GDM

- History of delivery of a macrosomic infant

- Presence of end organ damage associated with diabetes:

- Microvascular (retinopathy, neuropathy, nephropathy)

- Cardiovascular (coronary, cerebrovascular, peripheral)

- Presence of vascular risk factors:

- HDL-C $<1.0 \mathrm{mmol} / \mathrm{L}$ in men, $<1.3 \mathrm{mmol} / \mathrm{L}$ in women

- $\mathrm{TG} \geq 1.7 \mathrm{mmol} / \mathrm{L}$

- Hypertension

- Overweight

- Abdominal obesity

- Smoking

- Presence of associated diseases:

- History of pancreatitis

- Polycystic ovary syndrome

- Acanthosis nigricans

- Hyperuricemia or gout

- Nonalcoholic steatohepatitis

- Psychiatric disorders (bipolar disorder, depression, schizophrenia)

- HIV infection

- Obstructive sleep apnea

- Cystic fibrosis

- Use of drugs associated with diabetes:

- Glucocorticoids

- Atypical antipsychotics

- Statins

- Highly active antiretroviral therapy

- Antirejection drugs

Testing with $2 \mathrm{hPG}$ in a $75 \mathrm{~g}$ OGTT may be considered in individuals with FPG $6.1-6.9 \mathrm{mmol} / \mathrm{L}$ and $/$ or $\mathrm{A}_{1 \mathrm{c}} 6.0 \%-6.4 \%$ in order to identify individuals with IGT or diabetes.

Use of standardized measurement techniques and validated equipment for all methods (AOBP, non-AOBP, home BP monitoring and ambulatory BP monitoring) is recommended. Measurement using electronic (oscillometric) upper arm devices is preferred over auscultation. (Unless specified otherwise, electronic [oscillometric] measurement should be used.)

Four approaches can be used to assess BP:

- $A O B P$ is the preferred method of performing in-office BP measurement. When using AOBP, a displayed mean $\mathrm{SBP} \geq$ $135 \mathrm{~mm} \mathrm{Hg}$ or DBP $\geq 85 \mathrm{~mm} \mathrm{Hg}$ is high.

- When using non-AOBP, a mean SBP $\geq 140 \mathrm{~mm} \mathrm{Hg}$ or DBP $\geq 90 \mathrm{~mm} \mathrm{Hg}$ is high, and an SBP between 130 and $139 \mathrm{~mm} \mathrm{Hg}$ and/ or a DBP between 85 and $89 \mathrm{~mm} \mathrm{Hg}$ is high-normal.

- Using ambulatory BP monitoring, patients can be diagnosed as hypertensive if the mean awake SBP is $\geq 135 \mathrm{~mm} \mathrm{Hg}$ or the DBP is $\geq 85 \mathrm{~mm} \mathrm{Hg}$, or if the mean 24-hour SBP is $\geq 130 \mathrm{~mm} \mathrm{Hg}$ or the DBP is $\geq 80 \mathrm{~mm} \mathrm{Hg}$.

- Using home BP monitoring, patients can be diagnosed as hypertensive if the mean SBP is $\geq 135 \mathrm{~mm} \mathrm{Hg}$ or the DBP is $\geq 85 \mathrm{~mm} \mathrm{Hg}$. If the office BP measurement is high and the mean home BP is $<135 / 85 \mathrm{~mm} \mathrm{Hg}$, it is advisable to either repeat home monitoring to confirm the home BP is $<135 / 85 \mathrm{~mm} \mathrm{Hg}$ or perform 24-hr ambulatory BP monitoring to confirm that the mean 24-hr ambulatory BP monitoring is $<130 / 80 \mathrm{~mm} \mathrm{Hg}$ and the mean awake ambulatory BP monitoring is $<135 / 85 \mathrm{~mm} \mathrm{Hg}$ before diagnosing white coat hypertension. 


\section{Recommendation}

Screening of plasma lipids for men aged $\geq 40 \mathrm{yr}$; women aged $\geq 40 \mathrm{yr}$ (or postmenopausal). Consider earlier in ethnic groups (key supporting reference) at increased risk, such as South Asian or First Nations individuals.

Screen lipids at any age for:

- Clinical evidence of atherosclerosis

- Abdominal aortic aneurysm

- Diabetes mellitus

- Arterial hypertension

- Current cigarette smoking

- Stigmata of dyslipidemia (arcus cornealis xanthelasma or xanthoma)

- Family history of cardiovascular diseaseł

- Chronic kidney disease§

- Obesity (BMI $\geq 30 \mathrm{~kg} / \mathrm{m}^{2}$ )

- Inflammatory disease

- HIV infection

- Erectile dysfunction

- Chronic obstructive pulmonary disease

- Hypertensive diseases of pregnancy

Tobacco use status of all patients should be updated on a regular basis and health care providers should clearly advise patients to quit smoking.

Consider informing patients of their global risk to improve the effectiveness of risk factor modification. Consider also using analogies that describe comparative risk, such as "cardiovascular age," "vascular age," or "heart age" to inform patients of their risk status.

\section{Heart failure}

We recommend that patients with known or suspected heart failure should be assessed for multimorbidity, frailty, cognitive impairment, dementia and depression, all of which may affect treatment, adherence to therapy, follow-up or prognosis.

\section{Hypertension}

Global cardiovascular risk should be assessed. Multifactorial risk assessment models can be used to:

- Predict more accurately an individual's global cardiovascular risk

- Help engage individuals in conversations about health behaviour change to lower BP

- Use antihypertensive therapy more efficiently

In the absence of Canadian data to determine the accuracy of risk calculations, avoid using absolute levels of risk to support treatment decisions.

\section{Stroke}

Persons at risk of stroke and patients who have had a stroke should be assessed for vascular disease risk factors, lifestyle management issues (diet, sodium intake, exercise, weight, alcohol intake, smoking) and use of oral contraceptives or hormone replacement therapy.

Persons at risk of stroke should receive information and counselling about possible strategies to modify their lifestyle and risk factors. Referrals to appropriate specialists should be made where required. They may provide more comprehensive assessments and structured programs to manage specific risk factors.

Note: $2 \mathrm{hPG}=$ post-load glucose, $\mathrm{A}_{1 \mathrm{c}}=$ glycosylated hemoglobin, $\mathrm{ACR}=$ albumin-to-creatinine ratio, $\mathrm{AOBP}=$ automated office blood pressure, $\mathrm{BMI}=$ body mass index, $\mathrm{BP}=\mathrm{blood}$ pressure, C-CHANGE = Canadian Cardiovascular Harmonized National Guideline Endeavour, CCS $=$ Canadian Cardiovascular Society - Dyslipidemia, DBP $=$ diastolic blood pressure, DC $=$ Diabetes Canada (formerly Canadian Diabetes Association), eGFR = estimated glomerular filtration rate, FPG = fasting plasma glucose, GDM = gestational diabetes mellitus, $\mathrm{HC}=\mathrm{Hypertension}$ Canada, HF = Canadian Cardiovascular Society - Heart Failure, HDL-C = high-density liproprotein cholesterol, IFG = impaired fasting glucose, IGT = impaired glucose tolerance, OGTT = oral glucose tolerance test, $\mathrm{SBP}=$ systolic blood pressure, Stroke = Heart and Stroke Foundation, $\mathrm{TG}=$ triglycerides .

${ }^{\star}$ All recommendations are considered strong recommendations (Box 1); the quality of evidence supporting each recommendation varies (see Appendix 1 for a detailed discussion of the supporting evidence. Key references are indicated in this table.)

†Based on consensus opinion.

$\ddagger$ Men aged $<55 \mathrm{yr}$ and women aged $<65 \mathrm{yr}$ of age in first-degree relative.

$\S$ Chronic kidney disease: eGFR $<60 \mathrm{~mL} / \mathrm{min} / 1.73 \mathrm{~m}^{2}$ or ACR $>3 \mathrm{mg} / \mathrm{mmol}$ for at least 3-mo duration.

\section{Dyslipidemia}

For management of dyslipidemia, the Canadian approach is a treatto-target model. The Canadian Cardiovascular Society guideline for managing dyslipidemia in adults to prevent cardiovascular disease recommends pharmacologic therapy with statins for high-risk groups, including those with clinical atherosclerosis, abdominal aortic aneurysm, diabetes, chronic kidney disease, or low-density lipoprotein (LDL) cholesterol $\geq 5.0 \mathrm{mmol} / \mathrm{L}$, as well as a Framingham Risk Score of $\geq 20 \%$. However, for primary prevention, a risk assessment is required, as those with a risk score $<10 \%$ do not require pharmacotherapy, and a "fire-and-forget" strategy is inappropriate (i.e., treatment without follow-up blood tests to monitor lipid levels). 
For those at intermediate risk, there is consideration of therapy based on other risk factors, such as an $L D L \geq 3.5$, non-high-density lipoprotein (non-HDL) cholesterol $\geq 4.3$, apolipoprotein B-100 $\geq 1.2$, or men aged 50 years or older and women aged 60 years or older with one additional cardiovascular disease risk factor. These targets come from studies showing that achieving lower LDL levels was associated with better outcomes, ${ }^{75}$ that the proportional reduction of major cardiovascular events was directly related to the

\section{Table 5: Diagnostic strategies: New or updated recommendations in the 2018 C-CHANGE harmonized guideline*}

\section{Recommendation}

\section{Diabetes}

Diabetes should be diagnosed by any of the following criteria:

- $F P G \geq 7.0 \mathrm{mmol} / \mathrm{L}$

- $A_{1 c} \geq 6.5 \%$ (for use in adults in the absence of factors that affect the accuracy of $A_{1 c}$ and not for use in those with suspected type 1 diabetes)

- $2 \mathrm{hPG}$ in a $75 \mathrm{~g}$ OGTT $\geq 11.1 \mathrm{mmol} / \mathrm{L}$

- Random PG $\geq 11.1 \mathrm{mmol} / \mathrm{L}$

\section{Heart failure}

We recommend that BNP/NT-proBNP levels be measured to help confirm or rule out a diagnosis of heart failure in the acute or ambulatory care setting in patients in whom the cause of dyspnea is in doubt.

We recommend that patients who receive potentially cardiotoxic cancer therapy undergo evaluation of LVEF before the start of cancer treatments known to cause impairment in LV function.

\section{Hypertension}

Routine laboratory tests that should be performed for the investigation of all patients with hypertension include the following:

- Urinalysis

- Blood chemistry (potassium, sodium, and creatinine)

- Fasting blood glucose or $A_{1 c}$

- Serum total cholesterol, LDL-C, HDL-C, non-HDL-C, and triglycerides; lipids may be drawn fasting or nonfasting

- Standard 12-lead electrocardiography

Standardized office BP measurement should be used for follow-up. Measurement using electronic (oscillometric) upper arm devices is preferred over auscultation.

In patients with large arm circumference when standard upper arm measurement methods cannot be used, validated wrist devices (used with arm and wrist supported at heart level) may be used for blood pressure estimation.

$\mathrm{HF}^{32}$

$\mathrm{HF} \dagger$

$\mathrm{HC}^{34}$

Note: $2 \mathrm{hPG}=$ post-load glucose, $\mathrm{A}_{1 \mathrm{C}}=$ glycosylated hemoglobin, $\mathrm{BNP}=\mathrm{B}$-type natriuretic peptide, $\mathrm{BP}=$ blood pressure, $\mathrm{C}$-CHANGE = Canadian Cardiovascular Harmonized National Guideline Endeavour, DC = Diabetes Canada (formerly Canadian Diabetes Association), FPG = fasting plasma glucose, $\mathrm{FRS}=\mathrm{Framingham}$ Risk Score, $\mathrm{HC}=\mathrm{Hyperten}$ sion Canada, HF = Canadian Cardiovascular Society - Heart Failure, HDL-C = high-density lipoprotein cholesterol, LDL-C = low-density lipoprotein cholesterol, LV = left ventricle, LVEF = left ventricle ejection fraction, NT-proBNP = N-terminal pro B-type natriuretic peptide, OGTT = oral glucose tolerance test, $\mathrm{PG}=$ plasma glucose.

*All recommendations are considered strong recommendations (Box 1); the quality of evidence supporting each recommendation varies (see Appendix 1 for a detailed discussion of the supporting evidence. Key references are indicated in this table.)

†Based on consensus opinion.

\section{Table 6: Risk stratification: New or updated recommendations in the 2018 C-CHANGE harmonized guideline*}

\section{Recommendation}

\section{All}

We recommend that a cardiovascular risk assessment be completed every $5 \mathrm{yr}$ for men and women aged 40 to $75 \mathrm{yr}$ using the modified FRS or CLEM to guide therapy to reduce major cardiovascular events. A risk assessment might also be completed whenever a patient's expected risk status changes.

We recommend calculating and discussing a patient's "cardiovascular age" to improve the likelihood that patients will reach lipid targets and that poorly controlled hypertension will be treated.

We recommend sharing the results of the risk assessment with the patient to support shared decision-making and improve the likelihood that patients will reach lipid targets.

Note: C-CHANGE = Canadian Cardiovascular Harmonized National Guidelines Endeavour, CCS = Canadian Cardiovascular Society - Dyslipidemia, CLEM = Cardiovascular Life Expectancy Model, FRS = Framingham Risk Score.

*All recommendations are considered strong recommendations (Box 1); the quality of evidence supporting each recommendation varies (see Appendix 1, available at www.cmaj.ca/ lookup/suppl/doi:10-1503/cmaj.180194/-/DC1, for a detailed discussion of the supporting evidence. Key references are indicated in this table.)

$\mathrm{CCS}^{34}$

$\mathrm{CCS}^{34}$ 


\section{Diabetes}

All individuals with diabetes should follow a comprehensive, multifaceted approach to reduce CV risk, including:

- $\mathrm{A}_{1 \mathrm{c}} \leq 7.0 \%$ implemented early in the course of diabetes

- $\mathrm{SBP}$ of $<130 \mathrm{~mm} \mathrm{Hg}$ and DBP of $<80 \mathrm{~mm} \mathrm{Hg}$

- Additional vascular-protective medications in the majority of adult people with diabetes

- Achievement and maintenance of healthy weight goals

- Healthy eating

- Regular physical activity

- Smoking cessation

Therapy in most individuals with type 1 or type 2 diabetes should be targeted to achieve an $A_{1 c} \leq 7.0 \%$ to reduce the risk of microvascular and, if implemented early in the course of disease, CV complications.

In people with type 2 diabetes, an $\mathrm{A}_{1 \mathrm{c}} \leq 6.5 \%$ may be targeted to reduce the risk of chronic kidney disease and retinopathy if they are assessed to be at low risk of hypoglycemia based on class of antihyperglycemic medication(s) used, and the person's characteristics.

A higher $A_{1 c}$ target may be considered in people with diabetes with the goals of avoiding hypoglycemia and overtreatment related to antihyperglycemic therapy, with any of the following:

- Functionally dependent: $7.1 \%-8.0 \%$

- History of recurrent severe hypoglycemia, especially if accompanied by hypoglycemia unawareness: $7.1 \%-8.5 \%$

- Limited life expectancy: $7.1 \%-8.5 \%$

- Frail, older age or with dementia: $7.1 \%-8.5 \%$

- End of life: $A_{1 c}$ measurement not recommended. Avoid symptomatic hyperglycemia and any hypoglycemia.

An intensive healthy behaviour intervention program, combining dietary modification and increased physical activity, may be used to achieve weight loss, improve glycemic control and reduce CV risk.

\section{Dyslipidemia}

We recommend a target LDL-C consistently $<2.0 \mathrm{mmol} / \mathrm{L}$ or $>50 \%$ reduction of LDL-C in individuals for whom treatment is begun, to decrease the risk of CVD events.

Alternative target variables are $\mathrm{apoB}<0.8 \mathrm{~g} / \mathrm{L}$ or non-HDL-C $<2.6 \mathrm{mmol} / \mathrm{L}$.

We recommend a $>50 \%$ reduction of $L D L-C$ for patients with $L D L-C>5.0 \mathrm{mmol} / \mathrm{L}$ in individuals for whom treatment is begun, to decrease the risk of CVD events and mortality.

\section{Hypertension}

For nonhypertensive individuals (to reduce the possibility of becoming hypertensive) or for hypertensive patients (to reduce their BP), prescribe the accumulation of 30-60 min of moderate intensity dynamic exercise (e.g., walking, jogging, cycling or swimming) 4-7 d/wk in addition to the routine activities of daily living.

For high-risk patients aged $50 \mathrm{yr}$ or older, with SBP levels $\geq 130 \mathrm{~mm} \mathrm{Hg}$, intensive management to target an SBP of $\leq 120 \mathrm{~mm} \mathrm{Hg}$ should be considered. Intensive management should be guided by AOBP measurements. Patient selection for intensive management is recommended and caution should be taken in certain high-risk groups.

Antihypertensive therapy should be prescribed for average DBP measurements of $\geq 100 \mathrm{~mm} \mathrm{Hg}$ or average SBP measurements of $\geq 160 \mathrm{~mm} \mathrm{Hg}$ in patients without macrovascular target organ damage or other cardiovascular risk factors.

Antihypertensive therapy should be strongly considered for average DBP readings $\geq 90 \mathrm{~mm} \mathrm{Hg}$ or for average SBP readings $\geq 140 \mathrm{~mm} \mathrm{Hg}$ in the presence of macrovascular target organ damage or other independent cardiovascular risk factors.

People with diabetes mellitus should be treated to attain SBP of $<130 \mathrm{~mm} \mathrm{Hg}$ and DBP of $<80 \mathrm{~mm} \mathrm{Hg}$ (these target BP levels are the same as BP treatment thresholds).

\section{Obesity}

All those considering beginning a vigorous exercise program are encouraged to consult their physician or health care team professionals.

Note: $\mathrm{A}_{1 \mathrm{C}}=$ glycosylated hemoglobin, $\mathrm{AOBP}=$ automated office blood pressure, apoB = apolipoprotein B-100, $\mathrm{BP}=$ blood pressure, $\mathrm{C}-\mathrm{CHANGE}=\mathrm{Canadian}$ Cardiovascular Harmonized National Guideline Endeavour, CCS $=$ Canadian Cardiovascular Society - Dyslipidemia, CV $=$ cardiovascular, CVD $=$ cardiovascular disease, $\mathrm{DBP}=$ diastolic blood pressure, DC $=$ Diabetes Canada (formerly Canadian Diabetes Association), HC = Hypertension Canada, HDL-C = high-density liproprotein cholesterol, HF = Canadian Cardiovascular Society - Heart Failure, LDL-C = low-density liproprotein cholesterol, Obesity = Obesity Canada, SBP = systolic blood pressure.

*All recommendations are considered strong recommendations (Box 1); the quality of evidence supporting each recommendation varies (see Appendix 1 for a detailed discussion of the supporting evidence. Key references are indicated in this table.)

†Based on consensus opinion. 
absolute LDL reduction with no evidence of a threshold, ${ }^{76}$ that better outcomes were seen with at least a $50 \%$ reduction in LDL, ${ }^{77,78}$ and that intensification of statin therapy was associated with better outcomes in patients with cardiovascular disease..$^{39,79}$ The European Society of Cardiology ${ }^{80}$ and the American College of Cardiology $^{81}$ have recommended the use of targets as well.

\section{Diabetes}

The assessment of diabetes now includes testing with a two-hour plasma glucose after a $75 \mathrm{~g}$ oral glucose tolerance test for people with glycosylated hemoglobin $\left(A_{1 c}\right)$ levels from $6.0 \%$ to $6.4 \%$. Reliance on $A_{1 c}$ or fasting plasma glucose alone can miss impaired fasting glucose or impaired glucose tolerance ${ }^{82}$ and the oral

Table 8 (part 1 of 2): Pharmacologic and procedural therapy for CVD risk reduction: New or updated recommendations in the 2018 C-CHANGE harmonized guideline*

Recommendation

Source guideline (key supporting reference)

\section{Coronary artery disease or ischemic heart disease}

In people with established CVD, low-dose ASA therapy $(81 \mathrm{mg}$ ) should be used to prevent CV events.

$\mathrm{DC}^{45,46}$

Diabetes

Statin therapy should be used to reduce CV risk in adults with type 1 or type 2 diabetes with any of the following features:

- Clinical CVD

- Age $\geq 40 \mathrm{yr}$

- Age $<40 \mathrm{yr}$ and 1 of the following:

- Diabetes duration $>15 \mathrm{yr}$ and age $>30 \mathrm{yr}$

- Microvascular complications

- Warrants therapy based on the presence of other CV risk factors according to the 2016 CCS Guideline for the Diagnosis and Treatment of Dyslipidemia. ${ }^{4}$

In adults with type 2 diabetes with clinical CVD in whom glycemic targets are not achieved with existing antihyperglycemic medication, an antihyperglycemic agent with demonstrated CV outcome benefit (empagliflozin, liraglutide, canagliflozin) should be added to reduce the risk of major CV events.

- An SGLT2 inhibitor with demonstrated reduction in hospital admissions for heart failure may be added to reduce the risk of admission for heart failure.

ACE inhibitor or ARB, at doses that have demonstrated vascular protection, should be used to reduce CV risk in adults with type 1 or type 2 diabetes with any of the following:

- Clinical CVD

- Age $\geq 55$ yr with an additional CV risk factor or end organ damage (albuminuria, retinopathy, left ventricular hypertrophy)

- Microvascular complications.

\section{Dyslipidemia}

We recommend management that includes statin therapy in high-risk conditions including clinical atherosclerosis, abdominal aortic aneurysm, most DM, chronic kidney disease (age > $50 \mathrm{yr}$ ), and those with LDL-C $\geq 5.0 \mathrm{mmol} / \mathrm{L}$ to decrease the risk of CVD events and mortality.

For individuals not at LDL-C goal despite statin therapy as described above, a combination of statin therapy with second-line agents may be used to achieve the goal; the agent used should be selected based upon the size of the existing gap to LDL-C goal.

We recommend management that includes statin therapy for individuals at high risk (modified FRS $\geq 20 \%$ ) to decrease the risk of CVD events.

We recommend management that includes statin therapy for individuals at intermediate risk (modified FRS 10\%$19 \%$ ) with LDL-C $\geq 3.5 \mathrm{mmol} / \mathrm{L}$ to decrease the risk of CVD events. Statin therapy should also be considered for persons at intermediate risk with $\mathrm{LDL}-\mathrm{C}<3.5 \mathrm{mmol} / \mathrm{L}$ but with $\mathrm{apoB} \geq 1.2 \mathrm{~g} / \mathrm{L}$ or non-HDL-C $\geq 4.3 \mathrm{mmol} / \mathrm{L}$, or in men aged $\geq 50 \mathrm{yr}$ and women aged $\geq 60 \mathrm{yr}$ with $\geq 1 \mathrm{CV}$ risk factor.

\section{Heart failure}

We recommend that most patients with HFrEF be treated with triple therapy including an ACE inhibitor (or an ARB in those who are ACE-inhibitor intolerant), a beta blocker and an MRA unless specific contraindications exist.

We recommend loop diuretics be used to control symptoms of congestion and peripheral edema.

We suggest that NOACs should be the agent of choice for stroke prophylaxis in patients with HF and nonvalvular AF, and that the treatment dose be guided by patient-specific characteristics including age, weight and renal function.

We recommend that an ARNI be used in place of an ACE inhibitor or ARB, in patients with HFrEF who remain symptomatic despite treatment with appropriate doses of GDMT to decrease cardiovascular death, hospital admissions for heart failure, and symptoms. 
Table 8 (part 2 of 2): Pharmacologic and procedural therapy for CVD risk reduction: New or updated recommendations in the 2018 C-CHANGE harmonized guideline*

Recommendation

Source guideline

(key supporting reference)

\section{Hypertension}

Initial therapy should be with either monotherapy or single-pill combination.

$\mathrm{HC}^{58}$

- Recommended monotherapy choices are:

- A thiazide or thiazide-like diuretic, with longer-acting diuretics preferred,

- A beta-blocker (in patients $<60 \mathrm{yr}$ ),

- An ACE inhibitor (in patients who are not black),

- An ARB, or

- A long-acting CCB

- Recommended choices for single-pill combinations are those in which an ACE inhibitor is combined with a CCB, ARB with a CCB, or ACE inhibitor or ARB with a diuretic.

- Hypokalemia should be avoided in patients treated with thiazide or thiazide-like diuretic monotherapy.

Alpha-blockers are not recommended as first-line agents for uncomplicated hypertension; beta-blockers are not recommended as first-line therapy for uncomplicated hypertension in patients aged $\geq 60 \mathrm{yr}$; and ACE inhibitors are not recommended as first-line therapy for uncomplicated hypertension in black patients. However, these agents may be used in patients with certain comorbid conditions or in combination therapy.

For patients with stable angina pectoris but without prior heart failure, MI or coronary artery bypass surgery, either a beta-blocker or a CCB can be used as initial therapy.

\section{Stroke}

ASA (80-325 mg), combined ASA (25 mg) and extended-release dipyridamole (200 mg), or clopidogrel (75 mg) are all appropriate options; selection should depend on the clinical circumstances.

Patients with transient ischemic attack or ischemic stroke and nonvalvular AF should receive oral anticoagulation. In most patients requiring anticoagulants for AF, direct non-vitamin $\mathrm{K}$ oral anticoagulants should be prescribed in preference over warfarin.

When selecting choice of oral anticoagulants, patient-specific criteria should be considered.

Note: $\mathrm{ACE}=$ angiotensin-converting enzyme, $\mathrm{AF}=$ atrial fibrillation, apoB = apolipoprotein $\mathrm{B}-100, \mathrm{ARB}=$ angiotensin-receptor blocker, $\mathrm{ARN} \mathrm{I}=$ angiotensin receptor-neprilysin inhibitor ASA $=$ acetylsalicylic acid, CCB $=$ calcium channel blocker, CCS $=$ Canadian Cardiovascular Society - Dyslipidemia, $C V=$ cardiovascular, CVD $=$ cardiovascular disease, DC = Diabetes Canada (formerly Canadian Diabetes Association), DM = diabetes mellitus, FRS = Framingham Risk Score, HC = Hypertension Canada, HDL-C = high-density liproprotein cholesterol, $\mathrm{HF}=$ Canadian Cardiovascular Society - Heart Failure, HFrEF = heart failure with reduced ejection fraction, GDMT = guideline-directed medical therapy, LDL-C = low-density liproprotein cholesterol, MI = myocardial infarction, MRA = mineralocorticoid receptor antagonist, NOAC = new oral anticoagulant, $\mathrm{SGLT}=$ sodium-glucose cotransporter 2, Stroke = Heart and Stroke Foundation.

*All recommendations are considered strong recommendations (Box 1); the quality of evidence supporting each recommendation varies (see Appendix 1 for a detailed discussion of the supporting evidence. Key references are indicated in this table.)

†Based on consensus opinion.

glucose tolerance test is of benefit in patients with unexplained microvascular complications. It also helps to identify those who will benefit from a reduction in cardiovascular risk factors. ${ }^{83}$ Higher prevalence of hemoglobinopathies also reduce the accuracy of $A_{1 c}$ in high-risk non-Caucasian ethnic groups. ${ }^{84}$

The management of type 2 diabetes has been expanded with two new medication classes, the sodium-glucose cotransporter 2 (SGLT2) inhibitors and the glucagon-like peptide-1 (GLP-1) receptor agonists, with some members of each class showing reductions in major cardiovascular outcomes in addition to blood glucoselowering and, often, weight loss. ${ }^{85}$ An antihyperglycemic agent with proven cardiovascular benefit should be added to existing therapy to reduce cardiovascular outcomes. ${ }^{85}$ Addition of an SGLT2 inhibitor or a GLP-1 agonist is recommended for patients with uncontrolled diabetes and cardiovascular disease.

The current recommendation for an angiotensin-converting inhibitor or an angiotensin-receptor blocker in patients with dia- betes is for patients older than 55 years who have one additional cardiovascular risk factor, or clinical cardiovascular disease or microvascular complications. This is a change from previous recommendations that all people with diabetes older than 55 years should be treated with a renin angiotensin-aldosterone system blocker, considering the lack of evidence for cardiovascular benefits in the lower-risk population.

\section{Atrial fibrillation}

The use of direct oral anticoagulants is recommended for nonvalvular atrial fibrillation over warfarin, based on randomized controlled trials showing equal or greater reduction of stroke, equal or less major bleeding, less intracranial bleeding, and no net increase in coronary artery disease outcomes. We recognize that as yet there are no long-term data on the effect of new oral anticoagulants on coronary outcomes, in contrast to that for efficacy of warfarin. ${ }^{86}$ 
Box 2: Multifaceted care for patients with cardiovascular risk

- Healthy eating

- Regular physical activity

- Smoking cessation

- Management of blood glucose

- Control of blood pressure

- Vascular-protective medications, including statins and blockers of the renin-angiotensin aldosterone system

\section{Health behaviours}

Changes in recommendations regarding health behaviours include recognition that high sodium intakes (i.e., $>6 \mathrm{~g} / \mathrm{d}$ ) are associated with worse cardiovascular outcomes, particularly in people with hypertension. ${ }^{87}$ Avoiding a diet high in sodium and aiming for a total daily sodium intake toward $2 \mathrm{~g}$ ( $5 \mathrm{~g}$ of salt or $87 \mathrm{mmol}$ of sodium) per day is recommended to lower blood pressure in people with hypertension and to prevent or delay the new onset of hypertension in those at risk. ${ }^{74}$ For dietary intake, maintaining sufficient calories for a healthy body weight and consuming a diet that is enjoyable and culturally appropriate is an overarching goal; when combined with regular physical activity, as outlined by the Canadian Society of Exercise Physiology guideline, diet can help to prevent type 2 diabetes. ${ }^{88}$

Cigarette smoking is a well-established risk factor for vascular disease. There is now sufficient evidence for recommendations for screening and advising on smoking cessation, as well as the use of pharmacotherapy for smoking cessation. ${ }^{89}$ Much of the evidence is summarized in a Cochrane collaboration systematic review finding that brief physician advice to stop smoking led to clinically important increases in smoking cessation, and advice combined with pharmacotherapy increased cessation rates over advice alone. ${ }^{27,90}$

\section{Implementation}

Continuing professional development is an important method of disseminating guidelines to primary care practitioners. C-CHANGE's electronic continuing professional development modules are hosted on the College of Family Physicians of Canada's Prevention in Hand initiative website (www.preventioninhand .com/Modules.aspx), and are accredited by the college and the Royal College of Physicians and Surgeons of Canada. C-CHANGE education modules facilitate small-group, case-based practice workshops; each is codeveloped by a member of the College of Family Physicians of Canada.

C-CHANGE supports the development of implementation tools for provincial and regional applications by asking these groups to include a guideline developer as part of the process, to ensure that the adaptation is true to the original recommendation and able to receive C-CHANGE endorsement. ${ }^{18}$

Patients often have multiple comorbidities, complicated by conditions such as stroke or myocardial infarction. A disease-silo approach to care leads to the risk of fragmentation, overlooking treatable risk factors. C-CHANGE helps to promote patient care by bringing guidelines from multiple groups together, formatted so that members of the interprofessional team can collaborate to formulate a comprehensive treatment plan directed to patient priorities. This makes it easier to achieve integration of primary and specialty care and to align this with the patient's health outcome goals and preferences. ${ }^{91}$

The development of C-CHANGE guideline-based quality practice indicators, such as those in the CANHEART (Cardiovascular Health in Ambulatory Care Research Team) study, ${ }^{92}$ allow for surveillance and evaluation of primary care practice behaviours and can inform the guideline development process about practice gaps, or recommendations that may not be able to be implemented. Ongoing "real-world" surveillance of practice changes recommended by the C-CHANGE guideline is important to identify where "practice gaps" exist and where guideline implementation efforts are most needed. Use of the set of quality indicators developed by the CANHEART initiative (based on previous versions of the C-CHANGE guideline) has shown that health regions in Ontario with better adherence to these guidelines have fewer cardiovascular events. ${ }^{92,93}$

The Triple Aim Framework offers a foundation for health care providers to conceptualize health care with an emphasis on optimizing health for individuals and populations, and the health care experience. ${ }^{94}$ This framework considers the patient experience of care, health of populations and per capita cost of health care, all of which need to be considered simultaneously. Leveraging the C-CHANGE harmonization of cardiovascular guidelines, the "real-world" surveillance of current practices and quality indicators and patient experiences, health care providers and decision-makers may assess, evaluate and identify opportunities for health care improvement across many patients with comorbidities, in alignment with this framework.

Telehealth interventions that include technologies (social networking services, smart phone applications, and patient and clinician portals) may enhance the remote delivery, support and monitoring of interventions reflective of C-CHANGE recommendations and quality indicators. ${ }^{95}$ With respect to the importance of healthy behaviours in preventing and managing cardiovascular disease, technologies may provide patients with asynchronous or synchronous access to feedback from health care professionals, while giving health care practitioners insightful patient data on healthy behaviours, medication adherence and other health goals. Technology preferences should be tailored to meet the needs of the patient and provider, as well as being integrated with electronic medical records..$^{96,97}$

The next update of the C-CHANGE guideline is projected to be in 2021, dependent on sufficient changes in the existing recommendations, or sooner if warranted by new evidence that will substantially change primary care practice. During this time, C-CHANGE will provide feedback to the individual guideline groups on their recommendations.

\section{Other guidelines}

Table 9 highlights some recommendations from other guidelines that differ from those included in this C-CHANGE update. 
Table 9: National and international guidelines for the management of cardiovascular disease

\section{Organization}

Canadian Task Force on Preventive Health Care ${ }^{98}$

American College of Cardiology/American Heart Association Hypertension guideline ${ }^{67}$

European Society of Hypertension/European Society of Cardiology ${ }^{67}$

American Diabetes Association and European Association of the Study of Diabetes ${ }^{99}$

American College of Cardiology/American Heart Association Lipid guideline ${ }^{100}$

European Society of Cardiology $y^{101}$

\section{Recommendations}

Recommend measuring height and weight and calculating BMI at appropriate primary care visits.

Lowered the definition of hypertension to $130 / 80 \mathrm{~mm} \mathrm{Hg}$. Target blood pressure for all groups is now $<130 / 80 \mathrm{~mm} \mathrm{Hg}$.

Base diagnosis of hypertension on out-of-office BP measures ambulatory BPM and home BPM if possible, or repeated office measures. Treatment threshold for very high $\mathrm{CV}$ risk now 130/85 mm Hg. BP treatment recommended for BP 140/90 $\mathrm{mm} \mathrm{Hg}$ and higher in low-risk patients if no response to lifestyle intervention. Target BP < $140 / 90 \mathrm{~mm} \mathrm{Hg}$ in all patients, $<120 \mathrm{~mm} \mathrm{Hg}$ systolic if younger than 65 years, target systolic $130-139 \mathrm{~mm} \mathrm{Hg}$ if 65 years or older. ${ }^{102}$

Recommend in addition to metformin, adding the newer antihyperglycemic agents, including DPP4 inhibitor, SGLT2 inhibitor and GLP-1 RA, and all groups recommend an $A_{1 c}<7.0$ for most patients.

Did not recommend a specific target but did advocate more intensive therapy or combination for those who did achieve a good response to statins (i.e., $>50 \%$ reduction). Treat-to-target approach for lipid management, targeting an LDL-C $<1.8 \mathrm{mmol} / \mathrm{L}$ for very high-risk patients.

Note: $\mathrm{A}_{1 \mathrm{C}}=$ glycosylated hemoglobin, $\mathrm{BMI}=$ body mass index, $\mathrm{BP}=$ blood pressure, $\mathrm{BPM}=$ blood pressure monitoring, $\mathrm{CV}=\mathrm{cardiovascular}, \mathrm{DPP} 4=$ dipeptidyl peptidase-4, GLP-1 RA = glucagon-like peptide-1 receptor agonists, LDL-C=low-density liproprotein cholesterol, SGLT2 = sodium-glucose cotransporter 2.

\section{Gaps in knowledge}

Obesity impairs health with respect to physical, mental and social well-being. We recommend the assessment and management of obesity using body mass index and waist circumference measurements as initial screening tools; however, these measures are based on Caucasians. Because body fat distribution varies with different ethnicity, different ethnicity-specific cutpoints for body mass index and waist circumference may provide more accurate assessment of adiposity-related complications in specific populations. ${ }^{103}$

Other gaps include blood pressure measurement and treatment thresholds for home and ambulatory monitoring in people with diabetes, as well as the management of resistant hypertension.

\section{Conclusion}

The C-CHANGE Initiative has resulted in a comprehensive set of recommendations that provide a single national authoritative source for the primary care management of cardiovascular disease. C-CHANGE shows that Canada's national cardiovascular-focused guideline groups can produce rigorous harmonized recommendations that allow interprofessional teams to manage, collaboratively and confidently, Canadians who have and are at risk for cardiovascular disease. This set of recommendations can be implemented and disseminated to meet the regional needs of Canadians.

\section{References}

1. Centre for Addiction and Mental Health. CAN-ADAPTT Canadian smoking cessation clinical practice guideline. Toronto: Heart and Stroke Foundation. Available: www. strokebestpractices.ca/wp-content/uploads/2012/04/CAN-ADAPTT2.pdf (accessed 2018 Jun. 15)
2. Selby P, Hunter K, Rogers J, et al. How to adapt existing evidence-based clinical practice guidelines: a case example with smoking cessation guidelines in Canada. BMJ Open 2017;7:e016124.

3. Ezekowitz JA, O'Meara E, McDonald MA, et al. 2017 Comprehensive update of the Canadian Cardiovascular Society guidelines for the management of heart failure. Can J Cardiol 2017;33:1342-433.

4. Anderson TJ, Grégoire J, Pearson GJ, et al. 2016 Canadian Cardiovascular Society guidelines for the management of dyslipidemia for the prevention of cardiovascular disease in the adult. Can J Cardiol 2016;32:1263-82.

5. Dale LP, LeBlanc AG, Orr K, et al. Canadian physical activity guidelines for adults: are Canadians aware? Appl Physiol Nutr Metab 2016;41:1008-11.

6. National Institute for Health and Clinical Excellence (2017 update). The guidelines manual. London (UK): National Institute for Health and Clinical Excellence; 2017.

7. McAlister FA, van DS, Padwal RS, et al. How evidence-based are the recommendations in evidence-based guidelines? PLoS Med 2007;4:e250.

8. Young KJ, Kim JJ, Yeung G, et al. Physician preferences for accredited online continuing medical education. J Contin Educ Health Prof 2011;31:241-6.

9. Tobe SW, Stone JA, Walker KM, et al. Canadian Cardiovascular Harmonized National Guidelines Endeavour (C-CHANGE): 2014 update. CMAJ 2014;186: 1299-305.

10. Diabetes Canada Clinical Practice Guidelines Expert Committee; Houlden RL. Diabetes Canada 2018 clinical practice guidelines for the prevention and management of diabetes in Canada. Can J Diabetes 2018;42(suppl 1):S1-S5.

11. Nerenberg KA, Zarnke KB, Leung AA, et al. Hypertension Canada's 2018 Guide lines for diagnosis, risk assessment, prevention, and treatment of hypertension in adults and children. Can J Cardiol 2018;34:506-5.

12. Lau DC, Douketis JD, Morrison KM, et al. 2006 Canadian clinical practice guidelines on the management and prevention of obesity in adults and children [summary]. CMAJ 2007;176:S1-13.

13. Wein $\mathrm{T}$, Lindsay MP, Côté $\mathrm{R}$, et al. Canadian stroke best practice recommendations: Secondary prevention of stroke, practice guidelines, update 2017. Int J Stroke 2018; 13:420-43.

14. Guyatt GH, Oxman AD, Vist GE, et al. GRADE: an emerging consensus on rating quality of evidence and strength of recommendations. BMJ 2008;336:924-6.

15. Tu JV, Khan AM, Ng K, et al. Recent temporal changes in atherosclerotic cardiovascular diseases in Ontario: clinical and health systems impact. Can J Cardiol 2017;33:378-84 
16. Alabousi M, Abdullah $\mathrm{P}$, Alter DA, et al. Cardiovascular risk factor management performance in Canada and the United States: a systematic review. Can J Cardiol 2017;33:393-404.

17. Brouwers MCPD, Kho MEB, Browman GPMD, et al. AGREE II: advancing guideline development, reporting and evaluation in health care. CMAJ 2010;182:E839-42.

18. Tobe SW, Liu PP. What does the finding of hypertension tell us about cardiovascular risk profile even when blood pressure is controlled? Can J Cardiol 2013;29:526-7.

19. Sacks FM, Svetkey LP, Vollmer WM, et al. Effects on blood pressure of reduced dietary sodium and the Dietary Approaches to Stop Hypertension (DASH) diet. DASHSodium Collaborative Research Group [comments]. N Engl J Med 2001;344:3-10.

20. Estruch R, Ros E, Salas-Salvadó J, et al. Primary prevention of cardiovascular disease with a Mediterranean diet. [retraction; corrected and republished in N Engl J Med 2018;378:e34] N Engl J Med 2013;368:1279-90.

21. Pillay J, Armstrong MJ, Butalia S, et al. Behavioral programs for type 2 diabetes mellitus: a systematic review and network meta-analysis. Ann Intern Med 2015;163:848-60.

22. Brehm BJ, Seeley RJ, Daniels SR, et al. A randomized trial comparing a very low carbohydrate diet and a calorie-restricted low-fat diet on body weight and cardiovascular risk factors in healthy women. J Clin Endocrinol Metab 2003;88:1617-23.

23. Knowler WC, Barrett-Connor E, Fowler SE, et al.; Diabetes Prevention Program Research Group. Reduction in the incidence of type 2 diabetes with lifestyle intervention or metformin. N Engl J Med 2002;346:393-403.

24. Lind M, Tuomilehto J, Uusitupa M, et al. The association between HbAlc, fasting glucose, 1-hour glucose and 2-hour glucose during an oral glucose tolerance test and cardiovascular disease in individuals with elevated risk for diabetes. PLoS One 2014;9:e109506.

25. Myers MG, Godwin M, Dawes M, et al. Conventional versus automated measurement of blood pressure in primary care patients with systolic hypertension: randomised parallel design controlled trial. BMJ 2011;342:d286.

26. Doran B, Guo Y, Xu J, et al. Prognostic value of fasting versus nonfasting lowdensity lipoprotein cholesterol levels on long-term mortality insight from the National Health and Nutrition Examination Survey III (NHANES-III). Circulation 2014;130:546-53.

27. Hartmann-Boyce J, Stead LF, Cahill K, et al. Efficacy of interventions to combat tobacco addiction: Cochrane update of 2013 reviews. Addiction 2014;109:1414-25.

28. Grover SA, Lowensteyn I, Joseph L, et al. Patient knowledge of coronary risk profile improves the effectiveness of dyslipidemia therapy: the CHECK-UP study: a randomized controlled trial. Arch Intern Med 2007;167:2296-303.

29. Currie K, Rideout A, Lindsay G, et al. The association between mild cognitive impairment and self-care in adults with chronic heart failure: a systematic review and narrative synthesis. J Cardiovasc Nurs 2015;30:382-93.

30. Patnode CD, Evans CV, Senger CA, et al. Behavioral counseling to promote a healthful diet and physical activity for cardiovascular disease prevention in adults without known cardiovascular disease risk factors: updated evidence report and systematic review for the US Preventive Services Task Force. JAMA 2017;318:175-93.

31. Colagiuri S, Lee CM, Wong TY, et al. Glycemic thresholds for diabetes-specific retinopathy: implications for diagnostic criteria for diabetes. Diabetes Care 2011;34:145-50.

32. Anand IS, Claggett B, Liu J, et al. Interaction between spironolactone and natriuretic peptides in patients with heart failure and preserved ejection fraction: from the TOPCAT trial. JACC Heart Fail 2017;5:241-52.

33. Navigator Study Group; McMurray JJ, Holman RR, Haffner SM, et al. Effect of valsartan on the incidence of diabetes and cardiovascular events. N Engl J Med 2010;362:1477-90.

34. Grover SA, Hemmelgarn B, Joseph L, et al. The role of global risk assessment in hypertension therapy. Can J Cardiol 2006;22:606-13.

35. Gaede $\mathrm{P}$, Lund-Andersen $\mathrm{H}$, Parving $\mathrm{HH}$, et al. Effect of a multifactorial intervention on mortality in type 2 diabetes. N Engl J Med 2008;358:580-91.

36. Gerstein HC, Miller ME, Byington RP, et al. Effects of intensive glucose lowering in type 2 diabetes. N Engl J Med 2008;358:2545-59.

37. ADVANCE Collaborative Group, Patel A, MacMahon S, Chalmers J, et al. Intensive blood glucose control and vascular outcomes in patients with type 2 diabetes. $N$ Engl J Med 2008;358:2560-72.

38. Look Ahead Research Group; Wing RR. Long term effects of a lifestyle intervention on weight and cardiovascular risk factors in individuals with type 2 diabetes: four-year results of the Look AHEAD trial. Arch Intern Med 2010;170:1566-75.
39. Cannon CP, Blazing MA, Giugliano RP, et al. Ezetimibe added to statin therapy after acute coronary syndromes. N Engl J Med 2015;372:2387-97.

40. SPRINT Research Group, Wright JT Jr, Williamson JD, Whelton PK, et al. A randomized trial of intensive versus standard blood-pressure control. N Engl J Med 2015;373:2103-16.

41. van den Hoogen PC, Feskens EJ, Nagelkerke NJ, et al. The relation between blood pressure and mortality due to coronary heart disease among men in different parts of the world. NEngl J Med 2000;342:1-8.

42. Gu Q, Dillon CF, Burt VL, et al. Association of hypertension treatment and control with all-cause and cardiovascular disease mortality among US adults with hypertension. Am J Hypertens 2010;23:38-45.

43. Hansson L. The Hypertension Optimal Treatment study and the importance of lowering blood pressure. J Hypertens Suppl 1999;17:S9-13.

44. Chin SH, Kahathuduwa C, Binks M. Physical activity and obesity: what we know and what we need to know. Obes Rev 2016;17:1226-44.

45. Yusuf S, Zhao F, Mehta SR, et al.; Clopidogrel in Unstable Angina to Prevent Recurrent Events Trial Investigators. Effects of clopidogrel in addition to aspirin in patients with acute coronary syndromes without ST-segment elevation. [published errata in N Engl J Med 2001;345:1506 and N Engl J Med 2001; 345:1716] N Engl J Med 2001;345:494-502.

46. CURRENT-OASIS 7 Investigators, Mehta SR, Bassand JP, Chrolavicius S. Dose comparisons of clopidogrel and aspirin in acute coronary syndromes. [published erratum in N Engl J Med 2010;363:1585] N Engl J Med 2010;363:930-42.

47. Colhoun HM, Betteridge DJ, Durrington PN, et al. Primary prevention of cardiovascular disease with atorvastatin in type 2 diabetes in the Collaborative Atorvastatin Diabetes Study (CARDS): multicentre randomised placebo-controlled trial. Lancet 2004;364:685-96.

48. Marso SP, Daniels GH, Brown-Frandsen K, et al. Liraglutide and cardiovascular outcomes in type 2 diabetes. N Engl J Med 2016;375:311-22.

49. Zinman B, Wanner C, Lachin JM, et al. Empagliflozin, cardiovascular outcomes, and mortality in type 2 diabetes. N Engl J Med 2015;373:2117-28.

50. Neal B, Perkovic V, Mahaffey KW, et al. Canagliflozin and cardiovascular and renal events in type 2 diabetes. N Engl J Med 2017;377:644-57.

51. Yusuf S, Sleight P, Pogue J, et al. Effects of an angiotensin-converting-enzyme inhibitor, ramipril, on cardiovascular events in high-risk patients. The Heart Outcomes Prevention Evaluation Study Investigators [published errata in N Engl J Med 2000;342:748 and 2000;342:1376]. N Engl J Med 2000;342:145-53.

52. Baigent C, Landray MJ, Reith C, et al. The effects of lowering LDL cholesterol with simvastatin plus ezetimibe in patients with chronic kidney disease (Study of Heart and Renal Protection): a randomised placebo-controlled trial. Lancet 2011;377: 2181-92.

53. Ridker PM, Danielson E, Fonseca FAH, et al. Rosuvastatin to prevent vascular events in men and women with elevated c-reactive protein. $N$ Engl J Med 2008;359:2195-207.

54. Yusuf S, Bosch J, Dagenais G, et al. Cholesterol lowering in intermediate-risk persons without cardiovascular disease. N Engl J Med 2016;374:2021-31.

55. Zannad F, McMurray JJ, Krum H, et al. Eplerenone in patients with systolic heart failure and mild symptoms. N Engl J Med 2011;364:11-21.

56. Ruff CT, Giugliano RP, Braunwald E, et al. Comparison of the efficacy and safety of new oral anticoagulants with warfarin in patients with atrial fibrillation: a meta-analysis of randomised trials. Lancet 2014;383:955-62.

57. McMurray JJ, Packer M, Desai AS, et al. Angiotensin-neprilysin inhibition versus enalapril in heart failure. N Engl J Med 2014;371:993-1004.

58. Yusuf S, Lonn E, Pais $\mathrm{P}$, et al. Blood-pressure and cholesterol lowering in persons without cardiovascular disease. N Engl J Med 2016;374:2032-43.

59. ALLHAT Officers and Coordinators for the ALLHAT Collaborative Research Group. The Antihypertensive and Lipid-Lowering Treatment to Prevent Heart Attack Trial. Major outcomes in high-risk hypertensive patients randomized to angiotensin-converting enyzme inhibitor or calcium channel blocker vs diuretic; The Antihypertensive and Lipid-Lowering Treatment to Prevent Heart Attack Trial (ALLHAT). [published erratum in JAMA 2004;291:2196 and JAMA 2003;289:178] JAMA 2002;288:2981-97.

60. Antihypertensive and Lipid-Lowering Treatment to Prevent Heart Attack Trial Collaborative Research Group. Diuretic versus alpha-blocker as first-step antihypertensive therapy: final results from the Antihypertensive and Lipid-Lowering Treatment to Prevent Heart Attack Trial (ALLHAT). Hypertension 2003;42:239-46. 
61. Pepine CJ, Handberg EM, Cooper-DeHoff RM, et al. A calcium antagonist vs a noncalcium antagonist hypertension treatment strategy for patients with coronary artery disease. The International Verapamil-Trandolapril Study (INVEST): a randomized controlled trial. JAMA 2003;290:2805-16.

62. Baigent C, Blackwell L, Collins R, et al. Aspirin in the primary and secondary prevention of vascular disease: collaborative meta-analysis of individual participant data from randomised trials. Lancet 2009;373:1849-60.

63. Diener H-C, Aisenberg J, Ansell J, et al. Choosing a particular oral anticoagulant and dose for stroke prevention in individual patients with non-valvular atrial fibrillation: part 2. Eur Heart J 2017;38:860-8.

64. Flack JM, Calhoun D, Schiffrin EL. The New ACC/AHA hypertension guidelines for the prevention, detection, evaluation, and management of high blood pressure in adults. Am J Hypertension 2018;31:133-5.

65. Rabi DM, Padwal R. Intensive lowering of blood pressure: Should we SPRINT? CMAJ 2016;188:1067-8

66. Williamson JD, Supiano MA, Applegate WB, et al. Intensive vs standard blood pressure control and cardiovascular disease outcomes in adults aged $\geq 75$ years: a randomized clinical trial. JAMA 2016;315:2673-82.

67. Whelton PK, Carey RM, Aronow WS, et al. ACC/AHA/AAPA/ABC/ACPM/AGS/APhA/ ASH/ASPC/NMA/PCNA guideline for the prevention, detection, evaluation, and management of high blood pressure in adults: a report of the American College of Cardiology/American Heart Association Task Force on Clinical Practice Guidelines. J Am Coll Cardiol 2017; doi:10.1016/j.jacc.2017.11.006.

68. Daskalopoulou SS, Rabi DM, Schiffrin EL, et al. Hypertension guidelines in the United States and Canada: Are we getting closer? Hypertension 2018;71:976-8.

69. Muntner P, Carey RM, Gidding S, et al. Potential US population impact of the 2017 ACC/AHA high blood pressure guideline. Circulation 2018;137:109-18.

70. Kaczorowski J, Myers MG, Gelfer M, et al. How do family physicians measure blood pressure in routine clinical practice? National survey of Canadian family physicians. Can Fam Physician 2017;63:e193-9.

71. Myers MG. Automated office blood pressure-incorporating SPRINT into clinical practice. Am J Hypertens 2017;30:8-11.

72. Myers MG. The relationship between automated office and awake ambulatory blood pressure may be different at thresholds for diagnosis and target for therapy. Can J Cardiol 2018;34:8-10.

73. Armstrong D, Matangi M, Brouillard D, et al. Automated office blood pressure being alone and not location is what matters most. Blood Press Monit 2015;20:204-8.

74. Leung AA, Daskalopoulou SS, Dasgupta K, et al. Hypertension Canada's 2017 guidelines for diagnosis, risk assessment, prevention, and treatment of hypertension in adults. Can J Cardiol 2017;33:557-76.

75. Boekholdt SM, Hovingh GK, Mora S, et al. Very low levels of atherogenic lipoproteins and the risk for cardiovascular events: a meta-analysis of statin trials. J Am Coll Cardiol 2014;64:485-94.

76. Cholesterol Treatment Trialists' (CTT) Collaboration, Fulcher J, O'Connell R, Voysey $M$, et al. Efficacy and safety of LDL-lowering therapy among men and women: metaanalysis of individual data from 174000 participants in 27 randomised trials. Lancet 2015;385:1397-405.

77. Ridker PM, Mora S, Rose L. Percent reduction in LDL cholesterol following highintensity statin therapy: potential implications for guidelines and for the prescription of emerging lipid-lowering agents. Eur Heart J 2016;37:1373-9.

78. Bangalore S, Fayyad R, Kastelein JJ, et al. 2013 Cholesterol guidelines revisited: percent LDL cholesterol reduction or attained LDL cholesterol level or both for prognosis? Am J Med 2016;129:384-91.

79. Josan K, Majumdar SR, McAlister FA. The efficacy and safety of intensive statin therapy: a meta-analysis of randomized trials. CMAJ 2008;178:576-84.

80. Piepoli MF, Hoes AW, Agewall S, et al. 2016 European Guidelines on cardiovascular disease prevention in clinical practice: The Sixth Joint Task Force of the European Society of Cardiology and Other Societies on Cardiovascular Disease Prevention in Clinical Practice (constituted by representatives of 10 societies and by invited experts) Developed with the special contribution of the European Association for Cardiovascular Prevention \& Rehabilitation (EACPR). Atherosclerosis 2016;252:207-74.

81. Lloyd-Jones DM, Morris PB, Ballantyne CM, et al. 2016 ACC expert consensus decision pathway on the role of non-statin therapies for LDL-cholesterol lower- ing in the management of atherosclerotic cardiovascular disease risk: a report of the American College of Cardiology Task Force on Clinical Expert Consensus Documents. J Am Coll Cardiol 2016;68:92-125.

82. Chilelli NC, Cosma C, Ragazzi E, et al. Screening with HbAlc identifies only one in two individuals with diagnosis of prediabetes at oral glucose tolerance test: findings in a real-world caucasian population. Acta Diabetol 2014;51:875-82.

83. Gilmer TP, O'Connor PJ. The growing importance of diabetes screening. Diabetes Care 2010;33:1695-7.

84. Hare MJ, Magliano DJ, Zimmet PZ, et al. Glucose-independent ethnic differences in HbAlc in people without known diabetes. Diabetes Care 2013;36:1534-40.

85. Lipscombe L, Booth G, Butalia S, et al. Pharmacologic glycemic management of type 2 diabetes in adults. Can J Diabetes 2018;42:S88-103.

86. Macle L, Cairns J, Leblanc K, et al. 2016 focused update of the Canadian Cardiovascular Society guidelines for the management of atrial fibrillation. Can J Cardiol 2016;32:1170-85.

87. O'Donnell M, Mente A, Rangarajan S, et al. Urinary sodium and potassium excretion, mortality, and cardiovascular events. N Engl J Med 2014;371:612-23.

88. Balk EM, Earley A, Raman G, et al. Combined diet and physical activity promotion programs to prevent type 2 diabetes among persons at increased risk: a systematic review for the Community Preventive Services Task Force Combined Diet and Physical Activity Promotion Programs to Prevent Diabetes. Ann Intern Med 2015;163:437-51.

89. Daskalopoulou SS, Rabi DM, Zarnke KB, et al. The 2015 Canadian Hypertension Education Program recommendations for blood pressure measurement, diagnosis, assessment of risk, prevention, and treatment of hypertension. Can J Cardiol 2015;31:549-68.

90. Cahill K, Stevens S, Lancaster T. Pharmacological treatments for smoking cessation. JAMA 2014;311:193-4.

91. Tinetti ME, Esterson J, Ferris R, et al. Patient priority-directed decision making and care for older adults with multiple chronic conditions. Clin Geriatr Med 2016;32:261-75.

92. Tu JV, Maclagan LC, Ko DT, et al. The Cardiovascular Health in Ambulatory Care Research Team performance indicators for the primary prevention of cardiovascular disease: a modified Delphi panel study. CMAJ Open 2017;5:E315-21.

93. Tu JV, Chu A, Maclagan L, et al. Regional variations in ambulatory care and incidence of cardiovascular events. CMAJ 2017;189:E494-501.

94. Initiatives: The IHI Triple Aim. Boston (MA) Institute for Healthcare Improvement. Available: www.ihi.org/Engage/Initiatives/TripleAim/Pages/default.aspx (accessed 2018 Jun. 15)

95. Dorsey ER, Topol EJ. State of telehealth. N Engl J Med 2016;375:154-61.

96. Mignerat M, Lapointe L, Vedel I. Using telecare for diabetic patients: a mixed systematic review. Health Policy Technol 2014;3:90-112.

97. Davis RM, Hitch AD, Salaam MM, et al. TeleHealth improves diabetes selfmanagement in an underserved community: diabetes TeleCare. Diabetes Care 2010;33:1712-7.

98. Brauer P, Gorber SC, Shaw E, et al. Recommendations for prevention of weight gain and use of behavioural and pharmacologic interventions to manage overweight and obesity in adults in primary care. CMAJ 2015;187:184-95.

99. Inzucchi SE, Bergenstal RM, Buse JB, et al. Management of hyperglycaemia in type 2 diabetes, 2015: a patient-centred approach. Update to a position statement of the American Diabetes Association and the European Association for the Study of Diabetes. Diabetologia 2015;58:429-42.

100. Stone NJ, Robinson JG, Lichtenstein AH, et al. 2013 ACC/AHA guideline on the treatment of blood cholesterol to reduce atherosclerotic cardiovascular risk in adults: a report of the American College of Cardiology/American Heart Association Task Force on Practice Guidelines. J Am Coll Cardiol 2014;63(25 Part B):2889-934.

101. Catapano AL, Graham I, De Backer G, et al. 2016 ESC/EAS guidelines for the management of dyslipidaemias. Eur Heart J 2016;37:2999-3058.

102. Williams B, Mancia G, Spiering W, et al. 2018 ESC/ESH Guidelines for the management of arterial hypertension. Eur Heart J 2018;39:3021-3104.

103. Leiter LA, Fitchett DH, Gilbert RE, et al. Identification and management of cardiometabolic risk in Canada: a position paper by the cardiometabolic risk working group (executive summary). Can J Cardiol 2011;27:124-31. 
Competing interests: Todd Anderson reports receiving grants from Amgen and DalCor, and personal fees from Sanofi, Merck, and Amgen, outside the submitted work. Alice Cheng reports personal fees from Abbott, Boehringer Ingelheim, Eli Lilly, Janssen, Merck, Novo Nordisk, Sanofi, Servier and Takeda, outside the submitted work. Gord Gubitz reports receiving personal fees from Bayer, Pfizer and Boehringer Ingelheim, outside the submitted work. David Lau reports receiving research funding and speaker fees from AstraZeneca and Novo Nordisk and has received speaker fees and/or served as consultant from Amgen, Akcea, Boehringer Ingelheim, Janssen, Merck, Shire and Valeant, outside the submitted work. Lawrence Leiter has received research funding from, has provided CME on behalf of, or has acted as an adviser to Amgen, Astra Zeneca, Bayer, Boehringer Ingelheim, Eli Lilly, Esperion, GlaxoSmithKline, Janssen, Kowa, the Medicines Company, Merck, Novartis, Novo Nordisk, Resverlogix, Sanofi, Servier and The Medicines Company, outside the submitted work. Peter Selby reports receiving grants from Pfizer Inc., Bhasin Consulting Fund, Patient-Centered Outcomes Research Institute, Pfizer Canada Inc.; personal fees from Bristol-Myers Squibb, Pfizer Canada Inc., Evidera Inc., Johnson \& Johnson Group of Companies, Medcan Clinic, Miller Medical Communications, NVision Insight Group, Myelin \& Associates; and is a vendor of record for providing smoking cessation pharmacotherapy (free or discounted) for research studies for Pfizer, Novartis, Johnson \& Johnson, and MedPlan Communications, outside the submitted work. Simon Bacon has received consultancy fees from Schering-Plough, Merck and Sygesa, speaker fees from Novartis, and investigatorinitiated grants from GlaxoSmithKline and AbbVie. Sheldon Tobe reports grants from Eli Lilly, Astra Zeneca, AbbVie and Bayer, as well as personal fees from Servier and Valeant, during the conduct of the study. He has also had travel reimbursed by the Novartis Foundation. Sean Wharton reports personal fees from Novo Nordisk, Janssen and Eli Lilly, outside the submitted work. Eileen O'Meara reports clinical trial and national leader function fees paid to her institution from Novartis; clinical trial and national leader function fees paid to her instution, as well as consulting fees from Astra Zeneca; clinical trial fees paid to her institution from Merck; clinical trial fees paid to her institution and consulting fees from Bayer; and clinical trial and steering committee fees paid to her institution from Amgen. James Stone reports personal fees from Astra Zeneca, Bayer, Lilly, Sanofi, NovoNordisk and Servier, as well as personal fees for a clinical research trial from Sanofi, outside the submitted work. No other competing interests were declared.
Affiliations: Libin Cardiovascular Institute, Cumming School of Medicine (Anderson), University of Calgary, Calgary, Alta.; Department of Health, Kinesiology, and Applied Physiology (Bacon), Concordia University, Montréal, Que. \& Montreal Behavioural Medicine Centre, CIUSSS-NIM, Montréal, Que.; St. Michael's Hospital (Cheng), University of Toronto, Toronto, Ont.; McGill University (Daskalopoulou), Montréal, Que.; Department of Medicine (Ezekowitz), University of Alberta, Edmonton, Alta.; Institut de cardiologie de Montréal (Grégoire), Montréal, Que.; Université de Montréal (Gubitz), Montréal, Que.; Sunnybrook Research Institute (Hua-Stewart), Toronto, Ont.; Department of Family and Community Medicine (Jain), Sunnybrook Health Sciences Centre, University of Toronto, Toronto, Ont.; Institute of Health Policy, Management and Evaluation (Keshavjee), University of Toronto, Toronto, Ont.; Department of Nutritional Sciences (L'Abbé), University of Toronto, Toronto, Ont.; Department of Medicine and Libin Cardiovascular Institute (Lau), Cumming School of Medicine, University of Calgary, Calgary, Alta.; Li Ka Shing Knowledge Institute (Leiter), St. Michael's Hospital, University of Toronto, Toronto, Ont.; Heart and Stroke Foundation (Lindsay), Ottawa, Ont.; Ottawa Heart Institute (Liu), University of Ottawa, Ottawa, Ont.; Insitut de Cardiologie de Montréal (O’Meara), Université de Montréal, Montréal, Que.; Division of Cardiology, Mazankowski Alberta Heart Institute; University of Alberta, Faculty of Medicine and Dentistry (Pearson), Edmonton, Alta.; Departments of Medicine, Community Health and Cardiac Sciences (Rabi), University of Calgary, Calgary, Alta.; Centre for Addiction and Mental Health, Departments of Family and Community Medicine, Psychiatry and Public Health Sciences (Selby), University of Toronto, Toronto, Ont.; School of Nursing and Health Research Methods, Evidence and Impact, Faculty of Health Sciences (Sherifali), McMaster University, Hamilton, Ont.; Libin Cardiovascular Institute (Stone), University of Calgary, Calgary, Alta.; Division of Nephrology (Tobe), Sunnybrook Health Sciences Centre, University of Toronto, Toronto, Ont.; ICES, Sunnybrook Research Institute (Tu), University of Toronto, Toronto, Ont.; St. Joseph's Health Care Centre (Walker), Toronto, Ont.; McMaster University (Wharton), Hamilton Ont.; York University (Wharton), Toronto, Ont.

Contributors: Sheldon Tobe wrote the first and subsequent versions of the manuscript. James Stone, Peter Liu, Kimberly Walker and Diane Hua-Stewart are the executive members of C-CHANGE; Todd Anderson, Simon Bacon, Alice Cheng, Stella Daskalopoulou,
Justin Ezekowitz, Jean Grégoire, Gord Gubitz, Rahul Jain, Karim Keshavjee, Patty Lindsay, Mary L'Abbé, David Lau, Lawrence Leiter, Eileen O'Meara, Glen Pearson, Doreen Rabi, Diana Sherifali, Peter Selby, Mark Tremblay, Richard Ward and Sean Wharton are members of the C-CHANGE guideline panel. All members of the panel developed the 2018 C-CHANGE guideline, reviewed and made substantive contributions to the manuscript. All of the authors, with the exception of Jack Tu, approved the final version submitted for publication and agree to act as guarantors of the work.

${ }^{*}$ Dr. Jack Tu, a member of the C-CHANGE guideline panel, died on May 30, 2018, during preparation of this manuscript for publication.

Funding: Funding for the development of the 2018 C-CHANGE guideline was provided by the Canadian Vascular Network through a Canadian Institutes of Health Research Emerging Networks Grant (no. 132211). The C-CHANGE implementation tools and activities were funded by the Public Health Agency of Canada (no. 6464-15-201-8041132) and the Ontario Ministry of Health and Long-Term Care (no. 06668 and 0669). The funders did not have a direct influence on the process, the contents of the recommendations or the preparation of the manuscript.

Acknowledgements: The C-CHANGE executive (James Stone, Sheldon Tobe, Peter Liu, Diane Hua-Stewart and Kimberly Walker) acknowledges the insightful advice, wisdom and enthusiastic support of the following people who have contributed to the C-CHANGE process, the implementation or evaluation, and the 2018 update: Norman Campbell and Karen Tu; and for continuing professional development initiatives: David Dannenbaum, John Hickey, Thuy Pham, Sol Stern, Richard Ward and Sheila Hu. The executive also thanks Peter Jones and Alison Mulvale from the Ontario College of Art and Design University (OCADU) for designing the C-CHANGE guideline table in Appendix 1 , and for using C-CHANGE for the Inclusive Health Design program (MDes) at OCADU.

Endorsements: Canadian Action Network for the Advancement, Dissemination and Adoption of Practice-Informed Tobacco Treatment (CAN-ADAPTT); Canadian Cardiovascular Society; Canadian Association of Cardiovascular Prevention and Rehabilitation; Canadian Society for Exercise Physiology; Diabetes Canada; Hypertension Canada; Obesity Canada; Heart and Stroke Foundation.

Correspondence to: Sheldon Tobe, sheldon.tobe@sunnybrook.ca 